\title{
Gas Permeability Properties of Thermoplastic Polyurethane Modified Clay Nanocomposites
}

\author{
G. Shamini and K. Yusoh
}

\begin{abstract}
Interest in polymer nanocomposites bloomed over the last decades due to its unusual property improvements. A novel nanocomposite consisting of $\mathrm{Na}^{+}$montmorillonite nanoclay and polyurethane nanocomposite was successfully prepared using solution intercalation method. Nanoclay was modified using transition metal ions which were copper (II) chloride and iron (III) chloride to achieve good dispersion and to reduce clay agglomerations. The modification process proved to be successful through SEM micrographs. Gas permeability test was carried out in a Membrane Separation Testing Unit. Significant improvements in barrier properties were observed with the addition of modified montmorillonite. A remarkable four fold decrease was seen in polyurethane incorporated with $1 \%$ modified iron followed by a nearly threefold decrease in polyurethane incorporated with $1 \%$ modified copper when tested with oxygen gas. Polyurethane incorporated with $1 \%$ modified iron and copper also showed dramatic decreases of $60 \%$ and $50 \%$ respectively when tested with nitrogen gas.
\end{abstract}

Index Terms-Modification, montmorillonite, polyurethane, nanocomposites

\section{INTRODUCTION}

The field of polymer/clay nanocomposites has drawn great interest in the past decade due to its enhanced properties such as mechanical properties [1] and barrier properties [2], [3] compared to pristine polymers. One of the most prominent polymers that are featured in a wide range of end use properties is thermoplastic polyurethane (TPU). This can be attributed to its uniqueness whereby it has the elasticity of rubber combined with the toughness and durability of metal and its versatility due to the presence of soft and hard segments in its structure. TPU possesses great electrical and wear properties, weather resistance and mechanical properties, howbeit, it is reported to exhibit poor barrier properties [4]. These limitations of polyurethane can be ameliorated via two different approaches whereby the first is by changing the molecule structure through modification and the second is by introducing inorganic fillers into the polyurethane matrix [5]. The latter is often chosen to improve the properties of polyurethane.

Montmorillonite (MMT) clay is one of the renowned additives in polymer nanocomposites. It is widely used as it creates remarkable improvements in the properties of the polymer compared to its counter parts. Pure MMT is a hydrophilic phyllosilicate and it is only miscible with

Manuscript received August 4, 2013; revised November 1, 2013. This work was supported in part by the Fundamental Research Grant Scheme under Grant RDU 1203109.

Shamini Gunaseelan and Kamal Yusoh are with the Faculty of Chemical \& Natural Resources Engineering, Universiti Malaysia Pahang, 26300 Gambang, Pahang, Malaysia (e-mail:shamini_88@hotmail.com) hydrophilic polymers thus it is necessary to exchange alkali counter ions with cationic-organic surfactants in order to improve the compatibility of MMT with organic monomer or polymers [6]. The organic treatment is carried out through ion exchange between inorganic alkali cations on the clay surface with the desired organic cation such as primary, secondary, tertiary and quaternary alkylammonium or alkylphosphonium cations. Alkylammonium or alkylphosphonium cations provides functional groups that can react with the polymer matrix, and in some cases initiate the polymerization of monomers to improve the strength of the interface between the inorganic and the polymer matrix [7].

Recently, PU-MMT nanocomposites have been investigated widely to improve its properties as it has a broad field of applications in protective coatings, thermal insulators, packaging materials and containers, adhesives and moulding compound [8]. The improvement in the permeability properties of polyurethane is significant especially in its application as a packaging material and container.

This paper describes the preparation of polyurethane nanocomposites using conventional MMT and modified MMT. The morphological studies of the PU nanocomposites were done using Fourier transform infrared spectroscopy (FTIR) and scanning electron microscopy (SEM). The permeability property was analyzed using a Membrane Separation Testing Unit.

\section{EXPERIMENTAL}

\section{A. Materials}

The thermoplastic polyurethane used in this study was polyester based ESTANE* GP 75 AE NAT 021 THERMOPLASTIC purchased from Innovative Pultrusion Sdn. Bhd. The $\mathrm{Na}^{+}$montmorillonite nanoclays were purchased from Southern Clay Products. Other chemicals that were used in the study such as Chloroform 100Ppm Amylene Stabilised, Methanol, Iron(III) chloride hexahydrate, and Copper (II) chloride were purchased from Fisher Scientific (M) Sdn. Bhd.

\section{B. Methods}

\section{1) Modification of nanoclay}

The modification process was done using copper (II) chloride and iron (III) chloride [9]. The organoclay was washed before the transition metal ions (TMI) treatment. The clay $(2 \mathrm{~g})$ was placed in $40 \mathrm{ml}$ solvent which was methanol in this study and the suspension was vigorously stirred for 24 hours. The slurry was the filtered using vacuum pump and dried in vacuum oven for 12 hours at $80{ }^{\circ} \mathrm{C}$. The dried clay 
was placed in $0.30 \mathrm{M}$ TMI solutions using the same solvent as in the washing process for the ion exchange to occur. The suspension was stirred for 36 hours. After the TMI treatment, the samples were filtered and dried in vacuum for 12 hours at $80^{\circ} \mathrm{C}$.

\section{2) Preparation of polyurethane clay membrane}

The polyurethane montmorillonite membranes were prepared via solvent intercalation. Polyurethane pellets and the pristine clay were dried at $65^{\circ} \mathrm{C}$ for 12 hours prior to solvent intercalation in an attempt to reduce its humidity. $0.4 \mathrm{~g}$ of clay and $4 \mathrm{~g}$ of TPU was stirred in $12 \mathrm{ml}$ and $80 \mathrm{ml}$ of chloroform respectively. After one hour, the clay mixture is shifted to the TPU mixture and it is stirred for four hours at $80^{\circ} \mathrm{C}$ for complete mixing to occur. The mixture is then put under ultrasonification process before being casted in a petri dish. The solution is evaporated and the film obtained is used for the gas permeability analysis. The same method is repeated using the modified clays. Four types of samples that were obtained are pure polyurethane (PU), polyurethane incorporated with clay (PU-MMT), polyurethane incorporated with modified copper clay (PU-MMT Cu) and polyurethane incorporated with modified iron clay (PU-MMT Fe).

\section{3) Characterization}

The chemistry of the polyurethane clay composites were analysed in a Nicolet Avatar 370 DTGS infrared spectrophotometer provides with Fourier transform analysis (FTIR). The technique used in carrying out the analysis was attenuated total reflectance (ATR) technique whereby the Golden Gate single reflection Germanium was used as prism. All spectra were obtained in the absorbance mode. The morphology of the specimens was examined by scanning electron microscopy (SEM) using ZEISS EVO50 operating at an accelerating voltage of $10 \mathrm{kV}$. A thin coating of platinum was deposited into the polymer surface and attached to the stub to avoid electrostatic charging during the analysis.

\section{4) Gas Permeability Test}

The gas permeability analysis was done using Membrane Separation Unit. The permeation study was conducted using constant pressure method [10]. Two types of gases that were used are the oxygen gas and nitrogen gas. The feed side pressure of the membrane cell was maintained at 1.5 bar and the permeate side was maintained at atmospheric pressure. The gas permeability was determined from the following equation:

$$
p=\frac{q l}{\operatorname{At}\left(p_{1}-p_{2}\right)}
$$

where $p$ is permeability in barrer, $q$ is flow rate of the permeate gases passing through the membrane $\left(\mathrm{cm}^{3} / \mathrm{s}\right), l$ is the membrane thickness $(\mathrm{cm}), p_{1}$ and $p_{2}$ are the absolute pressures of the feed side and permeate side respectively $(\mathrm{cmHg})$ and $A$ is the effective membrane area $\left(\mathrm{cm}^{2}\right)$.

\section{RESUlTS AND DisCUSSION}

\section{A. FTIR Analysis}

Structural characteristic of polyurethane and polyurethane nanocomposites were carried out using FTIR analysis. The FTIR spectra of the composite membrane are shown in Fig. 1. Infrared absorptions bands that are commonly seen in polyurethane were observed in all four samples. The stretching vibration that were seen are the hydrogen bonded primary amines at $3300 \mathrm{~cm}-1$; stretching vibration of $\mathrm{CH} 2$ at 2994-2857 cm-1; stretching vibration due to the carbonyl present in urethane, urea and ester groups at $1730-1700 \mathrm{~cm}-1$ [11]. However as it can be seen in Fig. 1, there is an occurrence of an absorption band at $1040 \mathrm{~cm}-1$ for PU-MMT, PU-MMT Cu, and PU-MMT Fe. This is an indication of the presence of $\mathrm{Si}-\mathrm{O}$ bonds due to the incorporation of the clay [12].

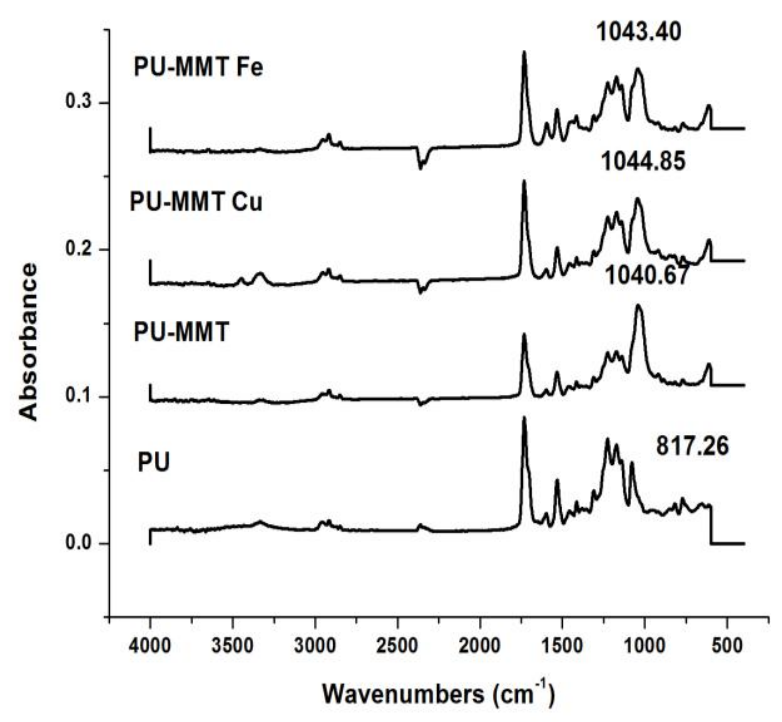

Fig. 1. FTIR spectra of polyurethane-silica nanocomposites.

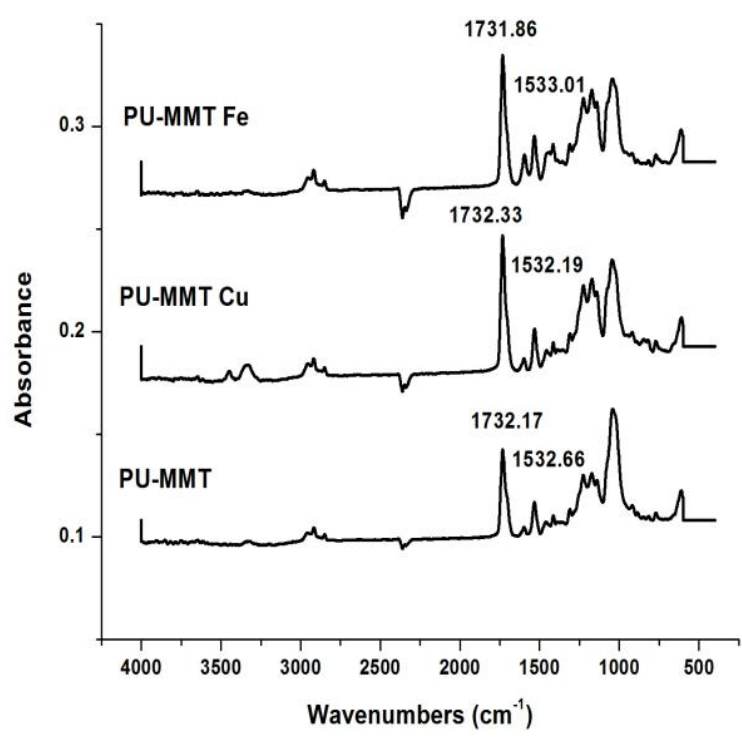

Fig. 2. FTIR spectra of carbonyl group in polyurethane nanocomposite.

The effects of silica nanoparticles on the phase separation of hard and soft segments of membranes are observed through the peaks that are related to the carbonyl group. The peaks appeared in lower frequency (around $1530 \mathrm{~cm}^{-1}$ ) refers to the bonded and the one appeared in higher frequency (around $1730 \mathrm{~cm}^{-1}$ ) refers to the free carbonyl. From the Fig. 2 , it can be seen that the free carbonyl peaks shifts towards the hydrogen bonded carbonyl bond and is slowly removed 
with the addition of clay [3]. With this observation, it can be said that the silicates were well distributed in the polymer matrix.

The spectra of nanocomposites which are modified with copper and iron shows that the NH stretch band near 3000 to $3500 \mathrm{~cm} \mathrm{~cm}^{-1}$ are shifted substantially to regions associated with ${ }^{+} \mathrm{NH}_{3}$ vibration which facilitate the ion exchange with MMT [13].

\section{B. SEM Analysis}

The SEM analysis in Fig. 3 and Fig. 4 showed that the modification on the clay was successful in reducing the clay agglomerations.

It can be seen in Fig. 3 that there are large clay agglomerates in the polymer matrix. Homogeneous dispersion of the clay into the polymer did not occur in this case.

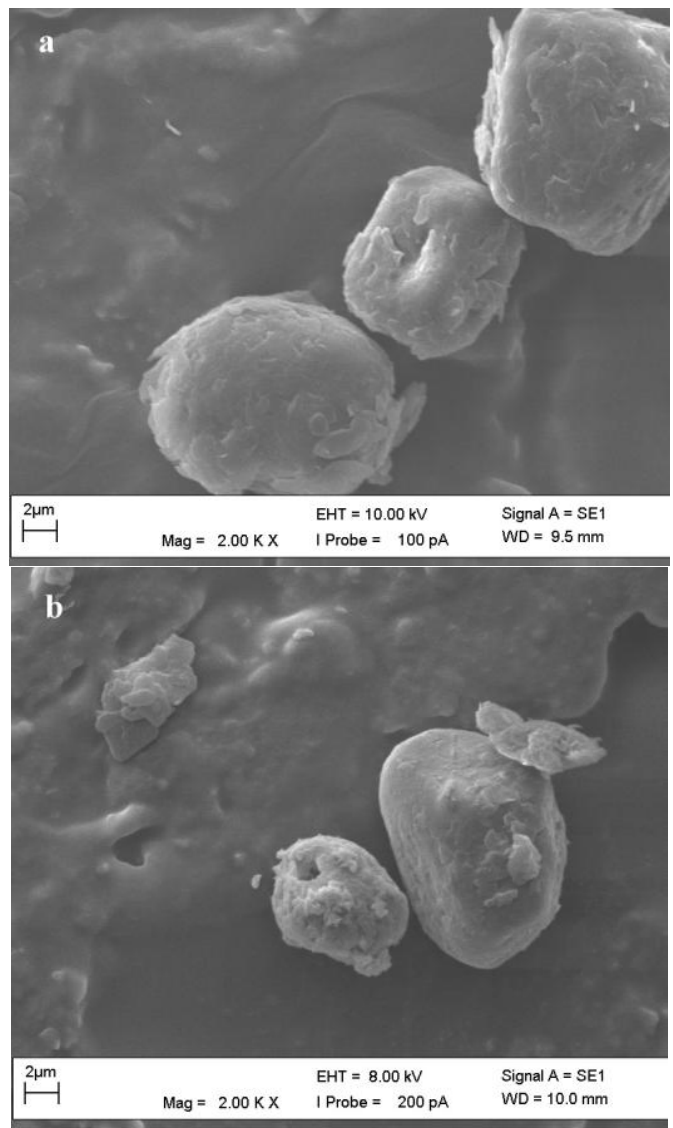

Fig. 3. SEM micrographs of (a) $1 \%$ PU-MMT (b) $3 \%$ PU-MMT.

However, with the TMI modification on the clay, better results were obtained. SEM micrograph in Figs. 4(a), (c) and (d) shows an intercalated clay structure with no evidence of big agglomerates. This suggests that the modifications done on the clay was successful in reducing the clay agglomerates and to promote better clay dispersion. In contrast, small sizes of clay aggregates can be noticed in Fig. 4(b). This can be associated to the poor distribution of the clay in the matrix whereby with a high percentage of clay loading (3\%), clay agglomerates tend to form. However, these agglomerates appear to be smaller compared to PU-MMT without modifications in Fig. 3.
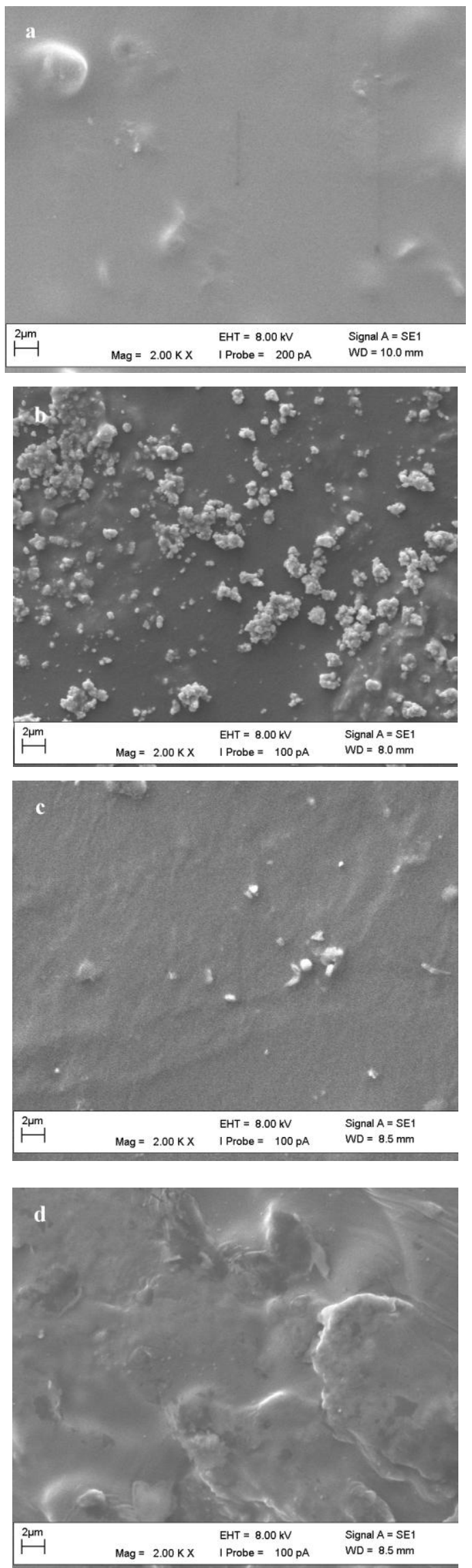

Fig. 4. SEM micrographs of (a) $1 \%$ PU-MMT Cu (b) $3 \%$ PU-MMT Cu (c) $1 \%$ PU-MMT Fe (d) $3 \%$ PU-MMT Fe.

Thus, it can be deducted that the modification of copper and iron into the clay was successful in reducing the clay agglomerations and aiding in improved clay dispersions. 


\section{Permeation Data}

The permeability values of PU, $1 \%$ and $3 \%$ of PU-MMT, PU-MMT Cu and PU-MMT Fe are shown in Fig. 5 and Fig. 6 and summarized in Table I.

TABLE I: NITROGEN AND OXYGEN PERMEABILITY COEFFICIENT

\begin{tabular}{|c|c|c|c|}
\hline Sample & $\begin{array}{ll}\text { Clay } & \text { Content } \\
(\mathrm{wt} \%) & \\
\end{array}$ & Permeability & Coefficient \\
\hline & & Nitrogen & Oxygen \\
\hline PU & 0 & 3.24 & 3.24 \\
\hline \multirow{2}{*}{ PU-MMT } & 1 & 3.08 & 2.62 \\
\hline & 3 & 2.23 & 2.36 \\
\hline \multirow{2}{*}{ PU-MMT Cu } & 1 & 1.63 & 2.39 \\
\hline & 3 & 1.55 & 2.02 \\
\hline \multirow[t]{2}{*}{ PU-MMT Fe } & 1 & 1.36 & 1.95 \\
\hline & 3 & 1.23 & 1.51 \\
\hline
\end{tabular}

In Table I, it can be seen that the addition of clay decreases the permeability coefficients. The coefficients decrease even further with the addition of modified clay. In the permeation analysis using nitrogen, the highest decrease was observed in $3 \%$ PU-MMT Fe which was $62 \%$ followed by $1 \%$ PU-MMT Fe that showed $58 \%$ decrease. The decrease in $1 \%$ and $3 \%$ PU-MMT Cu was 50\% and 52\% respectively. The decreases of permeability coefficient in polyurethane incorporated with modified clay were higher compared to pristine clay as shown in Fig. 5. The same pattern was observed with the permeability analysis that was done using oxygen gas as shown in Fig. 6. The highest decrease was seen again in $3 \%$ PU-MMT Fe which was $54 \%$ followed by $2 \%$ PU-MMT Cu that showed a decrease of $44 \%$.

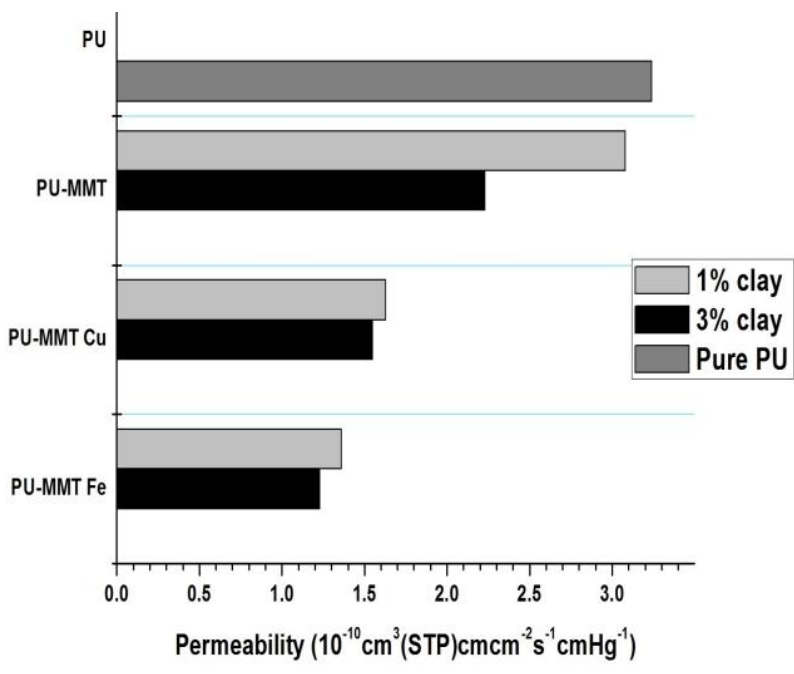

Fig. 5. Permeation rate in nitrogen gas.

Polyurethane that is incorporated with modified clay has lower permeability coefficients. The modification process promotes better clay dispersion and thus, the bond between the filler and the matrix is strengthened. This can be noticed in Fig. 4 whereby there are lesser clay agglomerates and smoother surface area. Due to this, the gases surpasses a though pathway with great difficulty and they require a long period of time.

The development of the interface regions between polymer bulk and clay sheets decreases the permeation rate. The filler particles in the membrane is said to be impermeable to the permeant molecules since it is uniformly and completely dispersed in the polymer [14]. The hard segmental that exists in the nanocomposites influences the transport process due to their ability to function as physical cross links. These hard segments restrict the chain mobility of the polymer and restrict the space created for diffusion of permeant molecules.

The incorporation of the modified clay into the polymer matrix was also found to decrease the gas permeability by forming a tortuous path [3]. In a tortuous path, the distances that the diffusing molecules must travel are maximized and this defines the decrease in the permeability coefficient as seen in Fig. 7.

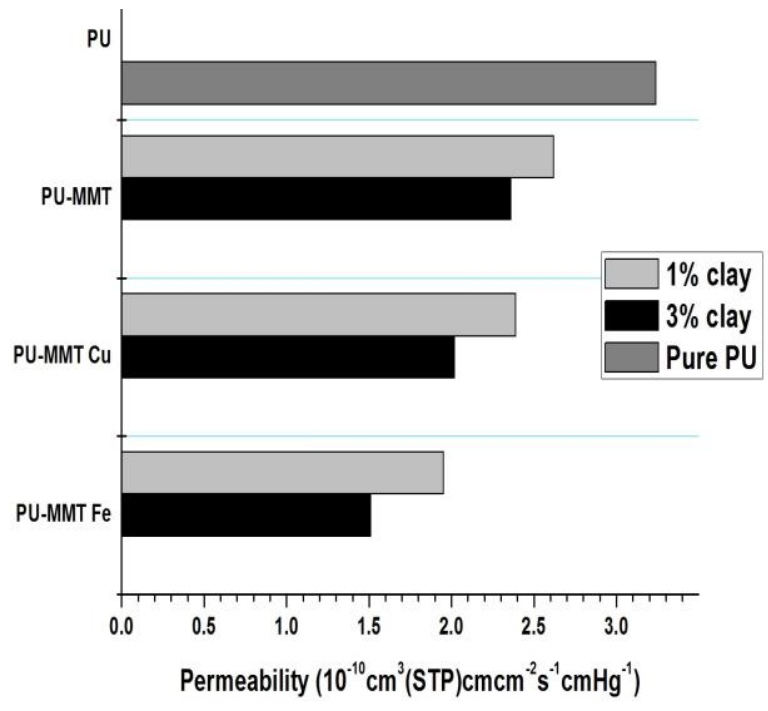

Fig. 6. Permeation rate in oxygen gas.

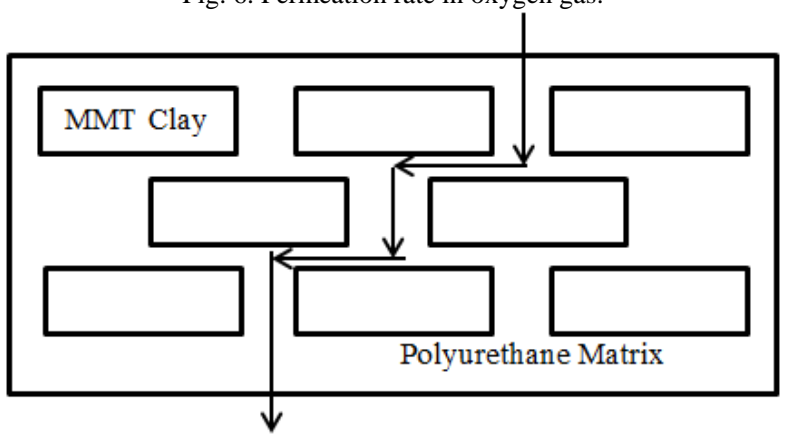

Fig. 7. Tortuous path in layered silicate nanocomposites.

Higher permeability rate was seen in oxygen gas compared to nitrogen gas in the polyurethane nanocomposites with modified clay. The diffusion coefficient of gases depends on the molecular size of the gas, rigidity and mobility of polymer chains and on the condensability of the gas [10]. The condensability of oxygen is $107 \mathrm{~K}$ compared to nitrogen which is $71 \mathrm{~K}$. Due to this, oxygen promotes higher solubility in the polymer. This leads to a higher permeability of this gas compared to nitrogen.

From the results, it can be observed that the polyurethane incorporated with modified clay portrays better permeability coefficients compared to pristine polyurethane. Thus, it can be deducted that the polyurethane modified clay is able to function as a better barrier material.

\section{CONCLUSION}

In this study, the effect of pristine and modified clay on the 
gas permeation properties of polyurethane membrane was investigated. The clay was modified using TMI iron (III) chloride and copper (II) chloride. The polyurethane nanocomposite membranes were prepared by solution intercalation method. The morphological studies of the polymer nanocomposites were done using FTIR and SEM. The presence of the clay was confirmed through FTIR whereas through SEM, it could be seen that the modifications process done reduced the clay agglomerates. The permeability coefficient of the PU decreased after it was incorporated with clay and the decrease was more significant with the addition of modified clay. It can be concluded that the incorporation of clay has successfully improved the barrier property of the polyurethane whereby this improvement can be seen to aid in packaging materials.

\section{ACKNOWLEDGMENT}

The first author is supported by a scholarship from the Ministry of Higher Education of the Government of Malaysia which is gratefully acknowledged.

\section{REFERENCES}

[1] K. Yusoh, J. Jin, and M. Song, "Subsurface mechanical properties of polyurethane/organoclay nanocomposite thin films studied by nanoindentation," Progress in Organic Coatings, vol. 67, pp. 220-224, February 2010.

[2] M. Jose, M. Eva, L. John, and C. Steven, "Transport properties in polyurethane/clay nanocomposites as barrier materials: effect of processing conditions," Journal of Membrane Science, vol. 337, pp. 208-214, July 2009.

[3] M. A. Osman, V. Mittal, M. Morbidelli, and U. W. Suter, "Epoxy-layered silicate nanocomposites and their gas permeation properties," Macromolecules, vol. 37, pp. 7250-7257, June 2004.

[4] X. Jiawen, L. Yunhang, Y. Xiaohui, W. and W. Xinling, "Thermal and mechanical properties of polyurethane/montmorillonite nanocomposites based on a novel reactive modifier," Polymer Degradation and Stability, vol. 86, pp. 549-555, December 2004.

[5] M. Song, H. S. Xia, K. J. Yao, and D. J. Hourston, "A study on phase morphology and surface properties of polyurethane/organoclay nanocomposite," European Polymer Journal, vol. 41, pp. 259-266, February 2005.

[6] G. L. Yuan, W. M. Li, S. Yin, F. Zou, K. C. Long, and Z. F. Yang, "Nanocomposites of urethane and montmorillonite clay in emulsion: In situ preparation and characterization," Journal of Applied Polymer Science, vol. 114, pp. 1964-1969, April 2009.

[7] M. Okamoto, "Recent advances in polymer/layered silicate nanocomposites: an overview from science to technology," Materials Science and Technology, vol. 22, pp. 756-779, November 2005.

[8] J. K. Kim, C. Hu, R. S. C. Woo, and M. L. Sham, "Moisture barrier characteristics of organoclay-epoxy nanocomposites," Composites Science and Technology, vol. 65, pp. 805-813, April 2005.

[9] P. Nawani, M. Y. Gelfer, B. S. Hsiao, A. Frenek1, J. W. Gilman, and S. Khalid, "Surface modification of nanoclays by catalytically active transition metal ions," Langmuir, vol. 23, pp. 9808-9815, May 2007.

[10] M. A. Semsarzadech, M. Sadeghil, M. Barikani, and H. Moadel, "The effect of hard segments on the gas separation properties of polyurethane membranes," Iranian Polymer Journal, vol. 16, pp. 819-827, December 2007.

[11] S. K. Wang, and C. S. P. Sung, "Spectroscopic characterization of model urea, urethane compound, and diamine extender for polyurethane-urea," Macromolecules, vol. 35, pp. 877-882, January 2002.

[12] Y. I. Tien and K. H. Wei, "The effect of nano-sized silicate layers from montmorillonite on glass transition, dynamic mechanical, and thermal degradation properties of segmented polyurethane," Journal of Applied Polymer Science, vol. 86, pp. 1741-1748, November 2002.

[13] A. Rehab, and N. Salahuddin, "Nanocomposite materials based on polyurethane intercalated into montmorillonite clay," Materials Science and Engineerng, A, vol. 399, pp. 368-376, June 2005.

[14] L. E. Nielsen, "Models for the permeability of filled polymer systems," Journal of Macromolecular Science: Part A - Chemistry, vol. 5, pp. 929-942, October 2006.

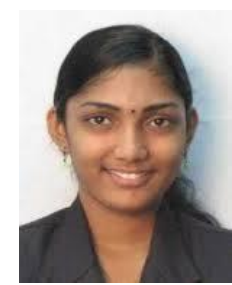

Shamini Gunaseelan was born in Perak, Malaysia, on August 1988. She obtained B. Eng. in Chemica from Universiti Malaysia Pahang, Malaysia, in 2012. Now, she is pursuing M. Eng in Faculty of Chemica \& Natural Resources Engineering in Universiti Malaysia Pahang. Her field of research is on Polymer Testing and Nanotechnology. 